U.S. government funds for either travel or academic expenses.

- Previous grant recipients are not eligible.

- The maximum award to an individual is $\$ 300$.

Applicants must complete a form available from the APSA national office and must have their department chairpersons write a letter of support for their applications. Applications without a letter of support will not be considered.

The deadline for the receipt of the complete application for a travel grant to the September 1-4, 1994 Annual Meeting is June 30. Application forms and further information are available by writing to : Foreign Advanced Graduate Student Travel Grant, APSA, 1527 New Hampshire Avenue, N.W., Washington, DC 20036-1290.

\section{Annual Meeting Short Courses}

Each year in conjunction with the APSA Annual Meeting, the Association and APSA Organized Sections offer a selection of short courses. The courses provide an opportunity for members to enhance their knowledge about a field and to reinvigorate their teaching and research. The 1994 short course selection is described below.

Short Courses are scheduled for the day before the Annual Meeting on Wednesday, August 31. A registration form with complete times, costs and descriptions is located in the back of this issue of $P S$ along with the preliminary program of the 1994 Annual Meeting. Preregistration by July 29 is strongly encouraged to ensure that appropriate course materials and reservations are prepared for you.

\section{Short Course 1: \\ The Leading Scholar Series: Short Course for Graduate Students}

This year, Nelson Polsby of the University of California, Berkeley, will continue the Leading Scholar series. The series is exclusively for graduate students and will focus on topics relating to the professional life as a political scientist. Registra- tion details are provided in the back of this issue of $P S$.

\section{Short Course 2: Interactive Video in Political Science Sponsor: The Organized Section on Computers and Multimedia}

The convergence of video and computer technology has led to the development of interactive video. Interactive video uses either a personal computer or a Macintosh to control a laser video disk so that you have random access to the various video clips and stills on the disk. This multimedia technology allows the computer to be useful in teaching value oriented, as well as behavioral oriented courses.

The full-day workshop on interactive video will be lead by Marc Triebwasser of Central Connecticut State University. The workshop sponsored by the APSA Organized Section on Computers and Multimedia will include: a general introduction to interactive video disks for the beginner; how interactive video can be used in teaching: a survey of available interactive video disks and other video materials in political science; how you can create your own interactive video disks on campus; the prospects for digital video and CDROMs; and the sources for video clips on disks and on VCR tapes.

Lab sessions will be conducted so that participants can gain hands-on experience. No prior knowledge of computers or video technology is required.

Because of the equipment needs for the hands-on portion of the workshop, it is important to register as soon as possible. No same day registration will be possible. Registration details are in the back of this issue of $P S$.

\section{Short Course 3: Model United Nations: A Workshop for Faculty on How to Prepare Students Sponsor: Organized Section on Internships and Experiential Education}

Model UNs can be enormously productive learning experience for student delegates involved. They learn the history, politics, and culture of a nation other than their own; they write position papers and resolutions advocating policies and defending the nation; and they negotiate and caucus with delegates from other nations. In the process, they begin to understand the nuances of foreign policy; they begin to appreciate the complexities of global issues, and they begin to see the world from a non-American and in many cases a non-western perspective. They also learn how frustrating it is to be a diplomat of an organization whose major powers are persuasive and not coercive in a nature.

This workshop is a "hands-on" experience for faculty designed to help them organize a student delegation for participation in a Model United Nations. The topics will include preparation of students, the research tools available, and the development of a course for credit.

Facilitators include James Jacobs of Wright State, Richard Reitano of Dutchess Community College, and Sheldon Williams of Austin College, all of who have many years of experience in participating in national and regional Model UNs. Mary Matragrano, the 1994 Secretary General of the National Model United Nations, will also be a facilitator. The program will include a visit and tour of the United Nations headquarters. Registration details are at the back of this issue of PS.

\section{Short Course 4: \\ New York City's \\ Intergovernmental World \\ Sponsor: Organized Section on Federalism and Intergovernmental Relations}

New York City has been characterized as a "labyrinth of wheels within a wheel, understood only by the managers.' Join policy experts, local, state, and federal representatives for an exciting and informative afternoon of briefings on this "labyrinth" within the current context of increased mandates and decreased aid. This short course will focus on the intergovernmental agenda of the new Giuliani administration, comparing its formulation 
and priorities with those of the Dinkins and Koch administrations. It will discuss issues like Staten Island's 1993 vote to secede, and will consider how-and how effectively-the City administration has organized to promote its agenda in Washington and in Albany in its first year. Additionally, the short course will focus on the politics of intergovernmental relations under the Intermodal Surface Transportation Act of 1991 (ISTEA). New York City's regional, national, and international transportation linkages span mass transit, highways, airports, and shipping. Thus the ISTEA focus can shed light on the effects of federal mandates for metropolitan planning and for increased state flexibility on the politics, jobs, and transportation services in New York as well as in other cities.

This short course will be held in the Board Room of the Metropolitan Transportation Authority, 347 Madison Avenue, New York, NY. Registration details are at the back of this issue of $P S$.

\section{Short Course 5: \\ Publishing: The Do's and Don'ts Sponsor: Women's Caucus in Political Science}

The Caucus workshop will provide all the basic information for scholarly publishing. Presenters will include: Carrie Mullins, Editor, SAGE Publications; Jennifer Knerr, Editor, Westview Publications; Edward Artinian, President, Chatham House Publishers; and Leo Weigman, Acquisitions Editor, Harper Collins Publishers. The program will be overseen by Jo Freeman. Edward Artinian co-authored "How to Find a Publisher in Political Science," in the June 1992 and 1994 issues of PS: Political Science \& Politics. Jo Freeman authored "Negotiating a College Textbook Contract" in the Winter 1984 issue of $P S$. Registration details are at the back of this issue of $P S$.
Short Course 6:

UN Peacekeeping Operations:

Past, Present and Future

Sponsor: Organized Section on

International Security and

Arms Control

The program will offer an opportunity to discuss the prospects of UN peacekeeping operations after the Cold War. It includes briefings at the United Nations with UN officials, the U.S. Mission to the United Nations, the United Nations Association of the United States, UN journalists, and the German Mission to the United Nations. Registration details are at the back of this issue of $P S$.

\section{Short Course 7:}

Policy-Oriented Grantsmanship

\section{Sponsor: Organized Section} on Public Policy

This workshop on policy-oriented grantsmanship will present examples of successful efforts to obtain grant funding for public policy research. The workshop will identify a variety of potential funding sources; assess the impact of grant funding on public policy research and teaching programs; and compare advantages and disadvantages of contract research with those of traditional grants.

Workshop directors will be: Irwin Feller, Director, Graduate School of Public Policy and Administration, Pennsylvania State University; Hank C. Jenkins-Smith, Director for Research, University of New Mexico Institute for Public Policy; Keith Mueller, Director, Nebraska Center for Rural Health Research; and Frank Scioli, Program Director, Political Science Program, NSF Division of Social, Behavioral and Economic Research. Registration details are at the back of this issue of $P S$.

Short Course 8:

Teaching Political Science With Cases Sponsor: The Pew Fellowship and the APSA Program Division on Teaching and Learning in Political Science

The purpose of this workshop is to provide participants with enough grounding in leading case discus- sion, electing and creating case materials, and integrating them into course structures to begin experimenting with cases in their own political science courses. The workshop will consist of demonstration case discussion involving participants in the role of students, exercises in planning and leading case discussions, explication of the case writing process, and information transfer on case resources. The workshop leaders will include Vicki Colich of CSU/San Marcos, David Wilsford of Georgia Tech, John Boehrer of Harvard University's John F. Kennedy School of Government, Pew Fellow and Fellowship staff. Registration details are at the back of this issue of $P S$.

Short Course 9:

Federalism and Party Finance: New Approaches to Regulation and New Data on State and National Parties Sponsor: Organized Section on Political Organization and Parties

This half-day session will com. bine a true "workshop" on new data available on state and national party organizations with a discussion of strategies and problems in regulating party finance in federal system. The first session will include an explanation of the newly regulatory scheme under which parties raise and spend funds related to federal elections, and new data that come from these regulatory changes. Scholars currently working with the data will discuss their experience, and participants will have the opportunity to receive data sets relevant to their research interests. The second session will involve regulators from the federal and state/local levels along with party officials in a discussion of the regulatory process in an environment where party priorities, state, and federal law are in conflict. Presenters will include Robert Biersack of the Federal Election Commission, Anthony Corrado of Colby College, Ruth Jones of Arizona State University, and Frank Sorauf of the University of Minnesota. Registration details are at the back of this issue of $P S$. 


\section{APSA \\ LEADING SCHOLARS SERIES}

This year's participant in the APSA Leading Scholars Series is Nelson W. Polsby, professor of political science at the University of California, Berkeley. The workshop is open to all graduate students; preregistration is required. The session on Wednesday afternoon, August 31, at the New York Hilton is a rare opportunity for graduate students to talk in an informal way about the professional and intellectual development of a major figure in the political science discipline.

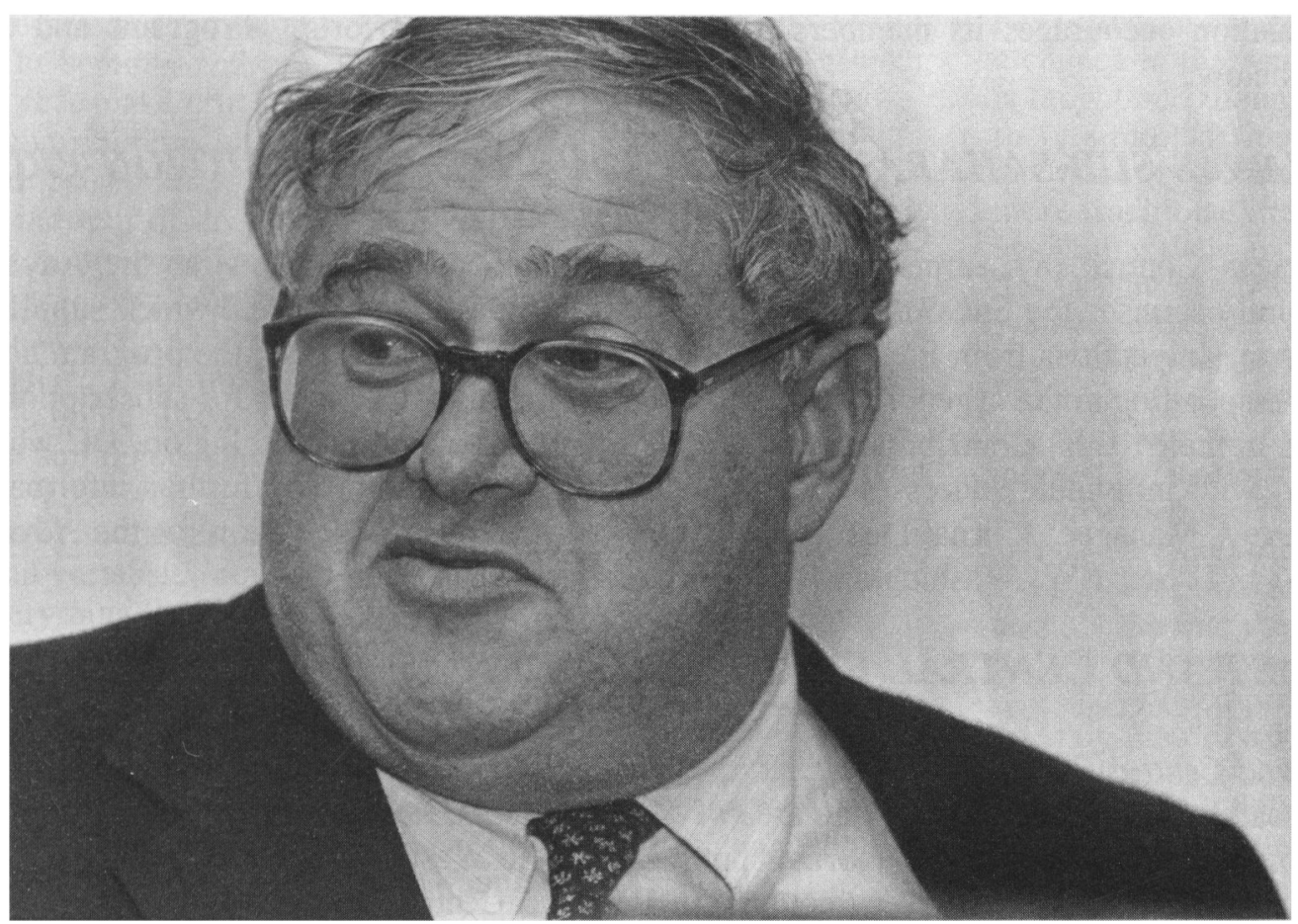

Nelson Polsby is a distinguished scholar, teacher, mentor, and member of the profession. He graduated Phi Beta Kappa from Johns Hopkins University and went on to get an M.A. from Brown University and a Ph.D. from Yale University. He taught at the University of Wisconsin and Wesleyan University before joining the faculty of UC-Berkeley. In addition to being a member of the Berkeley political science department, Polsby is director of the Institute for Governmental Studies, University of California, Berkeley.

Polsby served as Managing Editor of the American Political Science Review 1971-77, and in 1989 was Program Chair for the APSA Annual Meeting held in Atlanta. Other Association activities include the Hubert H. Humphrey Award Committee (1994), the Carey McWilliams Award Committee (1988, 1992), Scientific Information Exchange Committee (1972), the Charles E. Merriam Award Committee (1982), the Woodrow Wilson Award Committee (1980), and the APSA Nominating Committee (1986-87).

Polsby authored many articles and books including Community Power and Political Theory (1963), Congress and the Presidency (1964), Consequences of Party Reform (1983), and Political Innovation in America (1984). He coauthored Presidential Elections (1964).

To register for the session complete the form that appears in the back of this issue of $P S$. 


\section{HELP OPEN THE DOOR TO LEARNING FOR OTHERS}

Each year the American Political Science Association donates over 50 subscriptions of the American Political Science Review and PS: Political Science and Politics to Universities and Institutions worldwide in an effort to keep our colleagues abroad aware of current trends and research foci in the field of political science. The APSA makes these contributions through a number of organized donation projects. The Association encourages its members to participate in these efforts. Programs and contacts are described below.

\section{ACLS/AAAS SUB-SAHARAN AFRICA JOURNAL DISTRIBUTION PROGRAM}

The American Council of Learned Societies and the American Association for the Advancement of Science jointly sponsor the Sub-Saharan Africa Journal Distribution Program which supplies over 190 periodicals to Universities from Benin to Zimbabwe. Now in its sixth year, the program has continued its goal of responding to the urgent requests of African scientists and scholars for subscriptions to current periodicals in their fields. Contributions are sent to the AAAS office in Washington, DC where they are repackaged with individual addresses and shipped to the institutions. For further information contact Lisbeth Levey, Manager, Journal Distribution Program, American Association for the Advancement of Science, 1333 H St., NW, Washington, DC 20005.

\section{EAST AND CENTRAL EUROPEAN JOURNAL DONATION PROJECT}

The East and Central Europe Journal Donation Project, initiated by Arien Mack at the New School for Social Research, supplies journals in the area of social sciences, humanities, arts and law in an effort to allow scholars access to books and journals published in the West that have been non-existent till now. Participating libraries represent every country in East and Central Europe, the Baltic nations, several former Soviet republics and a number of the Balkan States. The program has been well received and has enlisted the help of ACLS and the United States Information Agency to further its aims. The New School identifies the recipients by circulating a list of available journals to the institutions who then choose the publications they wish to receive. Interested donors of back volumes or current subscriptions to important scholarly journals should contact Claudia Bedrick at The New School: (212) 229-5789.

\section{BRIDGES TO ASIA FOUNDATION}

The Bridges to Asia program acquires books, journals, newsletters, manuals, syllabuses, videos, and upper division and graduate level books for donation to universities and schools in China, the Philippines, Mongolia, Vietnam and Cambodia. Initiated in 1987 the program relies on the support of publishers and individual contributions of educational materials, including teaching aids such as overhead projectors and visual aids, through book drives and fundraisers. Donations should be packed in a carton or envelope with a list of the contents attached to the outside for Customs purposes. The Donations should be mailed to Bridges to Asia, Cargo Services - Pier 19, San Francisco, CA 94111. A copy of the list of contents should be sent to: Bridges to Asia, 1214 Webster Street, Suite F, Oakland, CA 94612. 
Short Course 10:

Identities and Institutions: Investigating Cultures, Structures and Subject

Sponsor: Organized Section Politics and History

This short course led by Victoria Hattam and Anne Norton will focus on series of debates, inquiries and critiques of new methods and fields of research concerning cultural studies and political culture, new institutionalism and poststructuralism, and the impact of feminism and race studies on the notion of the subject. The seminar will read both works that make crucial methodological contributions and works in politics, history, and related disciplines that put those insights and analyses into practice.

Cultures. Why traditional "political culture" is inadequate and what is emerging to replace it. In this field, new work in political science is drawing from - and influencingcultural studies and anthropology. The term "culture" no longer refers to a "residual variable," remaining after everything "political" has been precipitated. That leaves us with critical methodological questions. To begin with: Whenand how-is culture political?

Structures. The influence of the new institutionalism calls for a reexamination of the theoretical justifications for work on institutions. We will draw on work from Foucault, Luhmann and others who have given new energy to examinations of the structures and genealogies of states and institutions.

Subjects. Poststructuralism, critical race studies and feminism have given new energy to studies of identity even as they have put identity and subjects in question. We will address race and gender issues, the constitution of identities, methods for historicizing the rational actor, and critiques of identity politics.

The object of the short course is to clarify new methods for a more historical political science and a more rigorous examination of history. Registration details are in the back of this issue of $P S$.
Looking for Results: The Minority Graduate Fellowship Program, 1969-1994*

\section{David Stiepleman \\ American Political Science Association}

Descriptions of the American Political Science Association's Minority Graduate Fellowship Program are often confined to short paragraphs in promotional brochures. "In 1969," intones the measured voice of historical synopsis, "the APSA's Committee on the Status of Blacks in the Profession recognized the need to overcome the obstacles that were precluding minority students from pursuing advanced degrees in political science. ..."We learn that each year, promising students of political science are chosen as fellows and every doctoral department in the country is encouraged to provide them with financial assistance. We know that in 1983, the APSA began offering similar fellowships to Latino students and that as of this year, over 40 APSA fellows have earned their doctorates.

Though informational literature does not generally explain why it is important to take an active role in populating the discipline with more minority professors, the reasoning behind the Minority Fellowship Program is sound. The effort to open the profession to a more representative faculty came from a desire not only to improve the lot of young minority students whose talent for political science scholarship remained untapped, but in the belief that the addition of new, different faces and backgrounds to faculties was essential for the enrichment of political science itself.

"There is something wrong with political science," declared the Ad Hoc Committee on Mexican Americans in the Profession in 1970, "when we (1) fail to interpret the political presence of eight or more million people, and (2) when we fail to recruit and train more than a handful of their representatives" (Avalos 1991, 241). Jewel Prestage, the first African American woman to receive the doctorate in political science, wrote in 1969 that, further- more, the problems of the discipline were of great consequence outside the university. Political science, she insisted, is responsible for helping to bring about "a society more responsive to the needs of all its citizens"' (Prestage 1969, 23).

The Minority Graduate Fellowship Program was conceived to help push society toward being more representative and responsive, and it is sensible to determine if it is working. Are more minority professors being recruited and retained on political science faculties? If so, are they accounting for a change in the way the discipline is taught and thought about? Is there a more serious consideration of "minority politics" and are the more traditional areas of study reevaluating their approaches to politics in light of minority issues?

In addition, the measure of success for the APSA's Fellowship Program is not only a function of the discipline's intellectual development. The administrative aspects of the profession-tenure, for instance-are inextricably linked to the state of political science. If one accepts the fact that the areas collectively known as "minority politics" have been primarily developed by minority political scientists themselves (McClain and Garcia 1993), it is not difficult to see that the health of political science is dependent on parity in professional advancement.

$$
* * *
$$

In 1969, when the Minority Graduate Fellowship Program was begun, only 63 African Americans held a Ph.D. in political science. The APSA numbered 12,000 members at the time (Prestage 1969, 1). By 1977 , this number swelled to over 200 and from 1978 to 1980 , an additional 133 African Americans earned their doctorates (Woodard and Preston 1985, 81-2).

During this period, there was unprecedented growth in the fields of "minority politics," a reductive title for the emerging studies of African American, Latino, Asian American and Native American politics. The development of these fields, especially African American politics, ${ }^{1}$ is well-documented in 